\title{
Evasión molecular de la activación del macrófago bovino por Mycobacterium avium subespecie paratuberculosis
}

\author{
Molecular evasion of bovine macrophage activation by \\ Mycobacterium avium subspecies paratuberculosis
}

\begin{abstract}
René Ramírez G, ${ }^{1}$ M.Sc, Juan Maldonado $\mathrm{E}^{1 *}$ Ph.D.
${ }^{1}$ Universidad de Antioquia, Facultad de Ciencias Agrarias, Escuela de Medicina Veterinaria, Grupo de investigación Centauro, Laboratorio 233, Sede de Investigación Universitaria. Calle 67 № 53-108. Medellín, Colombia. *Correspondencia: juanguimal@gmail.com
\end{abstract}

Recibido: Julio de 2011; Aceptado: Febrero de 2013.

\section{RESUMEN}

El Mycobacterium avium subespecie paratuberculosis (MAP) es el agente causal de una enfermedad granulomatosica crónica, que afecta el tracto gastrointestinal de rumiantes domesticos y salvajes, conocida como la enfermedad de Johne o paratuberculosis. MAP es un microorganismo de crecimiento lento en cultivo, no obstante sobrevive in vivo en células fagocíticas mononucleares de los rumiantes, bajo condiciones de susceptibilidad individual, virulencia de la cepa infectante y estado inmune del individuo afectado. Una vez MAP es fagocitado por el macrófago bovino, tanto el macrófago como MAP activan: el uno para tratar de destruir a MAP y luego sufrir apoptosis y el otro para evadir su destrucción dentro del fagolisosoma del macrófago. El balance de dicha confrontación molecular determina el curso inicial de la infección hacia la eliminación eficiente del microorganismo o hacia el establecimiento de la infección, que culminará en los estadios III (clínico intermitente) y IV (clínica terminal) de la enfermedad de Johne. En la presente revisión se discuten los diferentes mecanismos moleculares por los cuales MAP evade la respuesta inmune, con énfasis en su comportamiento dentro de la vacuola fagocítica y como el agente establece mecanismos de sobrevivencia intracelular y altera la activación de los macrófagos del hospedero y de la respuesta inmune específica.

Palabras clave: Bacteria, evasión inmune, infecciones, inmunidad celular, paratuberculosis (Fuente: $C A B$ ). 


\begin{abstract}
Mycobacterium avium subspecies paratuberculosis (MAP) is the causing agent of a chronic granulomatous disease affecting intestinal tract of domestic and wild ruminants known as Johne's disease or paratuberculosis. MAP behaves as low growing mycobacteria In Vitro. However, it can survive into the phagocytic vacuole of macrophages of a susceptible In Vivo host. The infective capability of MAP depends on host susceptibility and they immune status at the time of infection and strain virulence of the mycobacteria. Once MAP is phagocytized by the bovine macrophage, specific profiles of gene transcription are produced into the bacteria, as well as within the macrophage genomes: MAP expresses genes related to survival into the phagolysosome that avoids its intracellular destruction and controls apoptosis of the infected macrophage, whereas macrophage expresses genes related to microbial processing and destruction within the phagocytic vacuole. The molecular events elicited by this encounter could drive the immune response of the host towards an efficient control of mycobacterial infection or towards the progression of the infection until establishment of Stages III (clinical intermittent) and IV (clinical terminal) of the disease. In this review we provide the reader with the basic concepts on the molecular mechanisms by which MAP can evade the host immune response, particularly on those processes related to its survival into the phagocytic vacuole that results in bacterial dissemination into the lymphoid system of a susceptible host.
\end{abstract}

Key words: Bacteria, cell mediated immunity, infections, immune evasion, paratuberculosis (Source: $C A B$ ).

\section{INTRODUCCIÓN}

Mycobacterium avium subespecie paratubeculosis $(M A P)$ es el agente etiológico responsable de la enfermedad de Johne; afección caracterizada por una enteritis granulomatosa crónica e incurable que afecta a los rumiantes domésticos y silvestres (1) y ha sido aislado de diferentes especies de mamíferos carnívoros y aves carroñeras (2). MAP es un microorganismo intracelular obligado (se multiplica in vivo en macrófagos; es ácidoalcohol resistente), muestra tinción positiva a la coloración Ziehl Neelsen. MAP requiere micobactina exógena para crecer en cultivo in vitro, la cual es un sideróforo capaz de captar el hierro (3), es producida por la mayoría de las micobacterias, excepto por MAP (4); situación que hace imprescindible su uso en el cultivo in vitro. MAP es muy resistente a las condiciones ambientales, puede permanecer viable durante 163 días en corrientes de agua, 270 días en aguas estancadas, 11 meses en materia fecal y suelos fertilizados, y 47 meses en materia orgánica desecada $(1,5)$. Este es uno de los aspectos que hace más dificil el control y la eliminación de MAP en un hato enzoótico.

La respuesta inmune del hospedero bovino contra MAP debe ser caracterizada por la producción de clones específicas de linfocitos $T$ ayudadores (CD4+) productores de citoquinas proinflamatorias como el INFY y el TNFa, que estimulan a los macrófagos a destruir la bacteria contenida en sus vacuolas fagocíticas (6); y de IL-2, que estimula a los linfocitos $T$ con actividad citotóxica (CD8+) y a las células NK a destruir los macrófagos infectados con MAP. Por el contrario, la producción de citoquinas antiinflamatorias como la IL-10, favorecen la permanencia de la bacteria (7), con diferencias en la respuesta en función de la raza afectada (8). Por otra parte, cepas virulentas de MAP han desarrollado mecanismos para evadir la respuesta antimicrobiana de los monocitos-macrófagos; logrando sobrevivir y multiplicar dentro de su fagosoma (9), evidencias que sugieren la existencia de una co-evolución de MAP encaminada a evadir los mecanismos de respuesta inmune del hospedero.

Los mecanismos usados por el microorganismo para evadir la respuesta microbicida del macrófago no están completamente dilucidados en el caso de la infección en bovinos, pero MAP puede evitar la unión de la vacuola fagocítica (o fagosoma) con los lisosomas, dentro del macrófago de tal manera que bloquea la presentación antigénica en moléculas de clase II del complejo mayor de histocompatibilidad (CMH) bovino -BoLA (10). Muchas vías de señalización están involucradas en la respuesta fagocítica del macrófago bovino contra los microorganismos intracelulares (11), las cuales MAP parece evadir para garantizar su sobrevivencia (12). Entre estas se cuenta las proteínas quinasas activadoras mitogénicas (MAPK) (13).

Por otra parte, la interacción entre los componentes de la pared celular de la micobacteria (14); tales como lipoarabinomanano (LAM), muramil dipéptido (MDP), y lipopolisacárido (LPS) con los receptores del macrófago del hospedero (15), juegan un papel importante en la sobrevivencia de MAP dentro del macrófago. Por consiguiente, en la presente revisión se presentan los conceptos 
básicos sobre los principales mecanismos moleculares que resultan de la fagocitosis de MAP por el macrófago y se presentan los procesos que deben ocurrir para una respuesta inmune adecuada contra el microorganismo o en su defecto, los procesos que desencadenan el establecimiento de la infección y su progresión hasta las fases clínicas de la enfermedad.

Ingreso de MAP a la mucosa digestiva. El primer contacto del bovino con MAP puede ocurrir en el feto de una vaca que esté infectada, lo cual implica que se encuentra expuesto al agente patógeno desde el ambiente uterino (16); luego, desde los primeros días de vida el neonato puede infectarse con MAP por vía oral (17). En las primeras horas después de su ingreso a través de la mucosa digestiva, MAP es captado por las células $M$ del tejido linfoide de la mucosa intestinal, para ser fagocitado por macrófagos sub-epiteliales residentes en el íleon distal, en los que puede sobrevivir y replicarse, para luego migrar hacia los linfonodos mesentéricos (18). Uno de los factores que participan en la adherencia inicial a la mucosa de MAP es la expresión de la proteína fijadora de fibronectina (FAPs, o Fibronecting Attaching Protein), (19) la cual le permite unirse a las integrinas de las células M (20) para facilitar el ingreso a la submucosa, donde encontrará los macrófagos.

La secuencia de eventos de la respuesta inmune innata del hospedero ante la infección inicial por MAP incluye el reclutamiento de los macrófagos hacia el sitio de la infección, seguido de su activación; proceso que desencadena la lisis bacteriana dentro de la vacuola facogítica, el procesamiento antigénico, el acoplamiento de los péptidos procesados a las moléculas clase II del complejo mayor de histocompatibilidad $(\mathrm{CMH})$ bovino. En este momento entra en acción la respuesta inmune específica, cuando el macrófago o la célula presentadora de antígeno (CPA) interactúa con los LT ayudadores (LT CD4+ con receptor gama-delta (LT-Y/ס) o alfa-beta (LT$\mathrm{a} / \beta)$ ), y con LT de tipo citotóxico (LT CD8+ (21)).

Los LT CD4+ interactúan con el macrófago infectado de manera directa cuando el receptor de antígeno del LT (TCR) reconoce los péptidos antigénicos de MAP procesados y presentados por el macrófago en su molécula $\mathrm{CMH}$ de clase II; o de manera indirecta, a través de la producción de citoquinas (22). El resultado de esta interacción es la activación de la fase aferente de la respuesta inmune específica, en donde se espera que ocurra la proliferación clonal de los LT que reconocerán los péptidos antigénicos de MAP, procesados por las CPA en sus moléculas CMH clase II, la producción de citoquinas promotoras de la actividad citotóxica, y la activación de la fase eferente de la respuesta que deberá culminar con la lisis intracelular del MAP por el macrófago y la destrucción de los macrófagos infectados por la actividad citotóxica de las células NK y los LT CD8+ estimulados por la IL-2.

Por ser un patógeno que se multiplica en el citoplasma de la CPA, la respuesta más efectiva contra MAP es la mediada por citoquinas tipo TH1, entre ellas el interferón gama (INF-g), el factor de necrosis tumoral tipo alfa (TNF-a) y la IL-2, las cuales estimulan los siguientes procesos: 1) en los macrófagos, el INF-g favorece la expresión de moléculas $\mathrm{CMH}$, la lisis intracelular de MAP mediante la activación de la producción de radicales del óxido nítrico (NO) y la activación de los procesos de apoptosis (junto con TNF-a); en las células NK, la IL-2 estimula la actividad citotóxica sobre los macrófagos infectados; y 3) en los LT CD8+, la IL-2 también estimula la actividad citotóxica sobre los macrófagos infectados. Es decir, que para una eliminación eficiente de MAP, debe predominar inicialmente, la generación de una respuesta inmune de tipo celular.

Por el contrario, en los hospederos susceptibles a la infección por MAP (bovinos que desarrollan las fases clínicas de la enfermedad), la generación de la respuesta efectora de tipo citotóxica está alterada; en su defecto, se desencadenan procesos asociados con la respuesta inmune de tipo humoral o TH2 (producción de anticuerpos contra los antígenos de MAP), la cual predomina sobre la inmunidad de tipo citotóxica, e impide la eliminación eficiente de MAP, en tanto que permite su proliferación en el citoplasma de los macrófagos infectados. Dicha alteración de la respuesta inmune es al parecer uno de los mecanismos de las cepas virulentas de MAP para causar la enfermedad.

\section{Componentes de membrana de MAP} implicados en la patogénesis. Las micobacterias poseen una pared celular compleja que les permite tener una eficiente capacidad de penetración a las células fagocíticas del hospedero (14), al igual que les confiere la habilidad para sobrevivir en condiciones ambientales difíciles (23). La pared celular de MAP es rica en lípidos, LAM y arabinomananos (AM), (24); componentes que son altamente inmunógenos, pero que desvían la respuesta del hospedero hacia la inmunidad de tipo humoral. Como evidencia de lo anterior, dichos componentes son altamente reactivos cuando se ponen en contacto con suero de vacas con paratuberculosis (25). Además, la pared celular de MAP contiene diversas proteínas que inducen la respuesta inmune humoral, puesto que contienen epitopes específicos de 
MAP (26). Algunos de estos componentes tienen la capacidad de modular la respuesta inmune del hospedero, a través de la modificación de las funciones del macrófago.

Entrada de MAP al monocito-macrófago. Como resultado de su interacción con el hospedero MAP ha generado muchos mecanismos para ingresar a las células fagocíticas a través de receptores específicos; una vez ingresan dentro del macrófago modifican la acididez del fagolisosoma (27) para impedir su destrucción dentro del mismo y modular la activación de diferentes vías de señalización que podrían conducir a su eliminación. Los receptores del macrófago que podrían verse involucrados en la fagocitosis de MAP incluyen los receptores del complemento (CR1, CR3, CR4), los receptores de inmunoglobulinas (FCR), el receptores de manosa (MR), el receptor de integrinas CD14 (20) y receptores tipo Toll (TLR, o Toll-Like Receptors), $(28,29)$.

El reconocimiento temprano de la micobacteria por componentes celulares de la inmunidad innata, parece involucrar TLRs, MR y receptores del complejo CD14/TLR4 (28). Algunos receptores de la familia de TLR están asociados con la infección por MAP, su activación por el ligando respectivo origina la cascada de activación de señales intracelulares que promueve la activación de las MAPK, y el factor NF-kB (29). A través de esta activación, el MAP induce la producción de IL-10, citoquina que puede inhibir la producción de las citoquinas pro-inflamatorias requeridas para el control eficiente de la infección por MAP, en especial por alterar la producción de IL12. Además, la producción temprana de IL-10 suprime la expresión de moléculas MHC clase I y clase II en la célula fagocítica (29), lo que altera el proceso de la presentación antigénica. Por otra parte, la activación del TLR2 altera la respuesta inmune efectiva contra MAP y propicia su proliferación dentro del macrófago.

En resumen, el procesamiento y acoplamiento de los péptidos antigénicos de MAP en moléculas CMH clase II (30), continua con su presentación al LT CD4+, seguido de la activación de los LT hacia un fenotipo funcional que produce citoquinas capaces de estimular la destrucción intracelular de MAP, por LT-CD8+ y por las células NK (31). En individuos susceptibles, MAP tiene la capacidad de alterar todos estos procesos para evitar su destrucción dentro del macrófago.

Evasión de la respuesta citotóxica en la invasión temprana de MAP. La destrucción primaria de patógenos intracelulares como MAP es responsabilidad de los LT CD8+ (CTL, o Cytotoxic T Lymphocytes) y las células NK activadas por IL-2 (células LAK o LymphokyneActivated Killer Cells). Sin embargo, los LT CD4+ pueden ser destruidos por LT citotóxicos que tienen TCR de tipo gama/delta (TCR Y/ס) (31), por consiguiente, procesos relacionados con la capacidad patogénica de MAP, al igual que alteraciones de la regulación de la activación de los LT del hospedero, parecen estar implicados en la sobrevicencia de MAP dentro del bovino susceptible a la infección.

Los LT CD4+ son los principales productores de INFY en bovinos infectados por MAP, seguidos de los CD8+; mientras que los LT $Y / \delta$ no la producen (33). En terneros infectados bajo condiciones experimentales, Ios LT CD4+ CD45RO (marcador de célula activada) y CD25+CD26+, fueron el tipo celular que presentó la mayor respuesta in vitro contra antígenos solubles de MAP. Asimismo, Ios LT $Y / \delta$ reactivos contra antígenos de MAP fueron hallados a partir de los 18 meses postinfección, mientras que los LT CD8+ mostraron poca proliferaron in vitro (33). Lo cual se podría interpretar como una evidencia de que en los animales que cursan hacia los estados crónicos de la paratuberculosis, la secuencia de eventos que deberían conducir a la eliminación de MAP y el control de su proliferación, están alterados.

Respuesta inmune celular en la infección por MAP. Los LT CD $4+$ con TCR $a / \beta$ son esenciales en el control de la infección por MAP y su activación posterior a la interacción con la CPA debe conducir a la producción de INFY, TNFa e IL-2 (34). Estos procesos son alterados por la producción de IL-10 inducida por algunas cepas de MAP en hospederos susceptibles a la infección, los cuales están asociados con alteración en la producción de IL-12p40 y la supresión de los genes responsables de la producción inducida de óxido nítrico necesario para la lisis del MAP en la vacuola fagocítica.

En estados subclínicos de la paratuberculosis bovina las células mononucleares de sangre periférica (MNSP) estimuladas con antígenos de MAP, producen cantidades abundantes de IL-10, pero tienen una disminución en la expresión de INFY. Por otra parte, bovinos infectados con MAP desarrollan células $\mathrm{T}$ reguladoras (T-reg) CD4+CD25+, capaces de producir IL-10 (35), citoquina que limita la activación de la respuesta de tipo citotóxica ante la infección micobacteriana (36).

Vías de señalización y síntesis de citoquinas por la célula fagocítica en la infección micobacteriana. Posterior a la fagocitosis de MAP por el macrófago se inician una serie de fenómenos de activación de la célula fagocítica, 
seguida de la síntesis de citoquinas, quimioquinas y metabolitos antimicrobianos (29). La mayor vía de señalización está relacionada con el inicio de la inflamación y la actividad antimicrobiana, lo que incluye la activación de las MAPK, fosfolipasa C, GTPasa Rho, proteína quinasa $C$, y fosfoinositidil 3 quinasa (PI3- quinasa), aumento de la concentración de calcio citosólico y Janus quinasa y aumento de activadores de transcripción (JAK/ STAT), (29,37).

Las vías de señalización MAPK y JAK/STAT1/2 son las vías prinsipalmente involucradas en la activación del macrófago y la respuesta antiinflamatoria (38), las citoquinas inflamatorias y el LPS $(29,38,39)$. La activación inicial de MAPKp38 promueve la expresión de IL-10, evento favorable para la micobacteria; por el contrario, la activación de MAPK ERK1 promueve la expresión de TNFa (13), evento favorable para la actividad microbicida del macrófago. Las cepas patógenas de MAP inducen preferencialmente la vía de señalización de MAPKp38 a través de su fosforilación, cuyo resultado es el aumento de la expresión de IL-10 $(13,40)$. La activación del receptor del IFNy induce su fosforilación y la activación de la vía de señalización JAK-STAT1/2; evento esencial para iniciar la transcripción de los genes de respuesta inmune estimulados por esta citoquina, dentro de los que se encuentran los responsables de estimular la producción de óxido nítrico por el macrófago, para la destrucción de MAP dentro de la vacuola fagocítica (41).

La activación del receptor de IFNy en la membrana del macrófago induce una respuesta bactericida por la generación de radicales de oxígeno y nitrógeno, la síntesis de citoquinas (IL-12 y TNFa), y la maduración del fagolisosoma. Las micobacterias patógenas suprimen la acción del INFy sobre la vía de señalización de JAK-STAT1/2 $(29,37)$; de esta manera, las citoquinas se convierten en un factor crítico en el desarrollo de la respuesta inmune ante el MAP. En los macrófagos la IL-10 y TGF $\beta$ son las dos citoquinas con mayor actividad inhibidora de la función fagocítica y presentadora de antígeno (22). La producción de INFy está disminuida en la fase clínica de la paratuberculosis bovina, en tanto que la administración de INFy exógeno estimula a los monocitos cultivados in vitro a controlar la infección por MAP $(35,42)$.

La IL-10 induce un cambio de la respuesta inmune hacia el fenotipo funcional Th2, puede inhibir la presentación antigénica por las células dendríticas y los macrófagos $(43,44)$. Algunas cepas de MAP inducen la producción abundante de IL-10, reducen la respuesta de LT al estímulo con INFy (31), mientras que in vitro regulan de manera negativa la producción de IL-12 por monocitos infectados e inhiben la producción de INFY por los LT Y/ठ (44). Durante las fases iniciales de la infección por MAP, los macrófagos (14) y las células NK (45) son una fuente importante de producción de ambas citoquinas proinflamatorias, varios días antes de que se genere la respuesta específica mediada por las células T con fenotipo funcional Th1. La principal función de la IL-10 consiste en suprimir la respuesta inmune tipo Th1 y con esto, alterar la actividad microbicida del macrófago (46), lo que favorece la evasión de la respuesta inmune efectiva contra MAP y propicia la formación de granulomas en los sitios de presencia de la bacteria, particularmente en la lámina propia del intestino delgado. EI MAP induce la fosforilación de MAPKp38 actuando a través de la unión de sus componentes de membrana con los receptores TLR2. Por ejemplo, la inhibición del TLR2 restaura la acidificación del fagosoma sin alterar la producción de IL-10 (13).

Mecanismos de sobrevivencia o muerte de
MAP en el monocito-macrófago. MAP tiene una alta capacidad de sobrevivir y adaptarse en el interior de la célula fagocítica, prevenir la activación del macrófago, bloquear la acidificación y maduración del fagolisosoma y atenuar la presentación de antígenos a los LT (29). Los macrófagos, están dotados de mecanismos de control de la infección micobacteriana (que funcionan de manera similar para todos las bacterias intracelulares (47); estos incluyen: a) la acidificación del fagosoma $(12,48)$, necesaria para la digestión enzimática de varios de los componentes estructurales de la bacteria; b) la producción de Óxido nítrico (NO) (34), de gran importancia para la eliminación de bacterias; y c) la apoptosis del macrófago después de la ingestión de la bacteria $(49,50)$, mediante el cual los macrófagos infectados son eliminados. MAP necesita ser fagocitado por el macrófago, luego de lo cual ocurre la acidificación y maduración del fagolisosoma (51); no obstante, algunas cepas de MAP tienen la capacidad de alterar este proceso, una vez están dentro de la vacuola fagocítica.

Los mecanismos usados por la micobacteria para controlar la maduración del fagosoma en el macrófago bovino, parecen involucrar muchos factores entre los que se cuentan la inhibición de la maduración del fagolisosoma, que puede ser mediado, al menos en parte, por el efecto directo de los lípidos intercalantes de la micobacteria en la membrana del fagosoma (12). En el proceso de alteración de la acidificación del fagosoma está presente la proteína Rab 5, pero no la proteína Rab7; estas proteínas pertenecen al grupo de la GTP-asas; proteínas que regulan 
la interacción de las membranas endosomales y su fusión con el lisosoma, para favorecer su unión y la combinación de sus contenidos en el fagolisosoma resultante. Rab5 estimula la fusión de fagosomas tempranos con los endosomas, mientras que Rab 7 lo hace con los endosomas tardíos y con el lisosoma (48). Por otra parte, el complejo lipoarabinan-manosa (Man-LAM), es al parecer, uno de los mayores responsables de la actividad inhibitoria de MAP sobre la fusión del fagolisosoma (29), así como de otras funciones antimicrobianas de los macrófagos en humanos (52). Por último, la disminución en la acidificación del fagosoma (53) ha sido relacionada con la persistencia de MAP.

Expresión génica en macrófagos y en MAP
durante el curso de la infección. Durante la infección de los macrófagos por MAP ocurre la regulación de múltiples genes relacionados con la inflamación, la estructura celular, las vías de señalización intracelular, la apoptosis y la trascripción génica $(54,55)$. Por otra parte, los perfiles de expresión génica varían en función del estado clínico de la enfermedad, en donde los macrófagos de vacas con estados subclínicos y clínicos de la paratuberculosis tienden a presentar un predominio de la supresión de genes, cuando son comparados con macrófagos cultivados in vitro (56). Los genes relacionados con la acidificación del fagolisosoma y con la apoptosis son los más implicados con la respuesta inmune efectiva contra MAP $(56,57)$. Además, algunas cepas de MAP modulan la expresión génica de los macrófagos infectados in vitro, de manera independiente de si son aislados de bovinos, humanos u ovejas (45).

Cuando se compara la expresión proteica de cepas de Mycobacterium avium subespecie avium (MAA) con la subespecie paratuberculosis (MAP), ocurre la transcripción de genes relacionados con la transcripción génica de la micobacteria (factores sygma) y han sido informadas importantes diferencias entre MAA y MAP, en donde MAP parece expresar un número limitado de factores sigma, al ser incubados en líneas celulares in vitro (58). De la misma manera, en estudios in vitro en los cuales se ha modificado la disponibilidad de nutrientes y de oxígeno a cepas de MAP provenientes de bovinos o de ovinos, se observó que MAP se adapta fácilmente a la hipoxia y a la privación de nutrientes (59).

En un estudio en el que se evaluó la expresión génica de MAP en la infección inicial, mediante el análisis de transcriptomas, a partir de muestras de ganglios linfáticos e intestino de bovinos con paratuberculosis sub clínica, se detectó que proporciones variables del genoma de MAP fueron detectadas en macrófagos ( $8 \%)$, íleon y linfonodo mesentérico (23\%) o en ambos compartimentos (3\%).

Además, en los aislamientos de intestino se halló sobreexpresión de genes relacionados con la síntesis de la pared celular y la latencia; mientras que en los macrófagos infectados se halló sobreexpresión de genes asociados con tráfico y migración intracelular (57). De igual modo, en dicho estudio se observó que en los macrófagos infectados in vitro con cepas de MAP aisladas de bovinos con enfermedad subclínica, predominó la expresión de genes relacionados con el metabolismo celular, la proliferación y biogénesis de la membrana y la pared celular a las 6 horas postinfección (p.i.); la expresión cambió al predominio de genes relacionados con viabilidad celular, biogénesis bacteriana y defensa bacteriana a las 48 horas p.i. ; seguido del predominio de genes relacionados con secreción y tráfico intracelular y defensa bacteriana, a las 120 horas p.i. (57).

Cuando se analizaron los transcriptomas del íleon predominó la expresión de genes relacionados con transcripción y metabolismo bacteriano; mientras que en los transcriptomas de linfonodos mesentéricos predominó la expresión de genes relacionados con la producción y conversión de energía así como el transporte y metabolismo de iones inorgánicos (57). De estos estudios se concluye que MAP es capaz de adaptarse a las condiciones que el ambiente tisular o intracelular del macrófago le exija, que en la infección temprana del macrófago predomina la expresión de genes relacionados con supresión de la respuesta inmune, y que cuando está en los tejidos predomina la expresión de genes que favorecen su crecimiento y proliferación.

Apoptosis de macrófagos después de la infección intracelular. Los macrófagos infectados con micobacterias activan sus propias vías apoptóticas poco después de la fagocitosis de la bacteria; sin embargo, las cepas patógenas de micobacterias inducen bajos niveles activación apoptótica. El complejo Man-LAM también estimula la fosforilación de una proteína preapoptótica denominada BAD, cuya fosforilación previene la unión de las proteínas anti apoptóticas $\mathrm{BCl}-2$ y BCl-XL. El Bcl-2 libre, previene la salida de citocromo $\mathrm{C}$ de la mitocondria. Las micobacterias patógenas también controlan la apoptosis por la inhibición del efecto del TNFa, mediante la inducción de la expresión de su receptor soluble (TNFR2), (37). 
Papel de los receptores de membrana en la supresión de la actividad microbicida del macrófago contra MAP. Los receptores de membrana y su grado de expresión están relacionados con la actividad microbicida de MAP en los macrófagos y con su actividad de presentación antigénica. MAP interviene con la presentación antigénica por la inhibición de la activación de enzimas proteolíticas en el fagosoma y la distribución de las moléculas $\mathrm{CMH}$ de clase I y clase II (30). Adicionalmente los macrófagos infectados por MAP no expresan $\mathrm{CMH}$ al ser estimulados por el INFY.

La presentación antigénica puede estar inhibida por proteinasas fagosomales, una de las cuales es la captesina $D$, la cual se encuentra inactiva en el fagosoma temprano, pero está activa en el fagosoma maduro (29); en tanto que está alterada en los fagosomas que contienen cepas virulentas de MAP. Otros mecanismos implican la acción de la IL10 , por su efecto sobre la expresión de las moléculas del complejo mayor de histocompatibilidad clase II, CD80, CD86 y las ICAM-1 en la membrana celular del macrófago (60).

MAP es un microorganismo altamente adaptado para evadir la respuesta inmune del hospedero bovino, en especial por su capacidad para alterar todos los mecanismos dependientes de la activación del macrófago. Los resultados de los estudios convencionales sobre la interrelación entre el MAP y los macrófagos del hospedero, han sido corroborados por los estudios de genómica y proteómica.

La expresión génica de los macrófagos bovinos infectados por MAP sugiere que las cepas patógenas, los bovinos susceptibles y otros factores inherentes a la relación individuoagente-ambiente, determinan en gran medida la progresión de una infección inicial hacia la eliminación de la bacteria, siempre y cuando los macrófagos y las CPA sean capaces de modular la respuesta inmune específica, de tal manera que predomine la producción de citoquinas que favorezcan la lisis intracelular de MAP y la eliminación de los macrófagos infectados por la vía apoptótica o mediante la citotoxicidad ejercida por las células NK o por los LT CD8+. De lo contrario, ocurrirá una activación de la vía relacionada con el fenotipo Th2, en cuyo caso el animal afectado tendrá una infección que cursará con los cuatro estadios de la enfermedad de Johne, hasta culminar indefectiblemente en el estadio IV (clínico terminal) de la enfermedad.

Perspectiva de investigación en la respuesta inmune contre MAP. Tan sólo en la década 2010-2020 se tendrán los resultados de estudios que hagan un análisis integral de las relaciones genéticas con la patogenia y la persistencia de una cepa particular y con su capacidad para causar la enfermedad. Por consiguiente, el entendimiento de los mecanismos que utiliza MAP para sobrevivir en los macrófagos será fundamental en la presente década, con el fin de desarrollar alternativas tecnológicas y terapéuticas para el control de la paratuberculosis bovina.

Por otra parte, se requiere diseñar estudios que evalúen en un modelo natural de la enfermedad en hatos enzoóticos, la progresión de la respuesta inmune desde la infección inicial hasta del desarrollo de las formas sub clínicas y clínicas, y su relación con los diferentes momentos fisiológicos de la vaca, para discernir el efecto que los factores estresantes relacionados con el parto, la lactancia y le presión metabólica de la producción láctea, puedan tener sobre la respuesta inmune del animal infectado por MAP.

De la misma manera, se debe estudiar por qué sólo una baja proporción de bovinos en un hato enzoótico desarrollan los estados clínicos de la enfermedad. Con el desarrollo de nuevas tecnologías y con una inversión adecuada en investigación científica, los mecanismos de evasión de la respuesta inmune innata y específica y la sobrevivencia de MAP podrán ser dilucidados y de esta manera se hará una contribución importante al entendimiento de la patogénesis de esta enfermedad y de otros bacterias intracelulares que afectan la salud de los animales y del humano.

\section{Agradecimientos}

Las actividades de la línea de investigación en inmunología veterinaria (paratuberculosis bovina) fueron financiadas por la Universidad de Antioquia, a través de la Vicerrectoría de Investigación (Convocatoria CODI mediana cuantía del año 2007). 


\section{REFERENCIAS}

1. Clarke C J. The pathology and pathogenesis of paratuberculosis in ruminants and other species. J Comp Pathol 1997; 116:217-261.

2. Stevenson $K$, Alvarez J, Bakker D, Biet F, de Juan L, Denham S, et al. Occurrence of Mycobacterium avium subspecies paratuberculosis across host species and European countries with evidence for transmission between wildlife and domestic ruminants. BMC Microbiol 2009; 9:212. doi:10.1186/1471-2180-9-212.

3. Francis J, Macturk HM, Madinaveitia J, Snow GA. Mycobactin, a growth factor for Mycobacterium johnei. I. Isolation from Mycobacterium phlei. Biochem J 1953; 55:596-607.

4. Matthews PR, McDiarmid A, Collins $P$, Brown A. The dependence of some strains of Mycobacterium avium on mycobactin for initial and subsequent growth. J Med Microbiol 1978; 11:53-57.

5. Zapata MM, Rodas JD, Maldonado JG. "Paratuberculosis bovina: ¿conocemos la situación real de la enfermedad en la ganadería colombiana?" Rev Colomb Cienc Pecu 2008; 21:420-435.

6. Burrells C, Clarke CJ, Colston A, Kay JM, Porter J, Little $D$, et al. Interferon-gamma and interleukin-2 release by lymphocytes derived from the blood, mesenteric lymph nodes and intestines of normal sheep and those affected with paratuberculosis (Johne's disease). Vet Immunol Immunopathol 1999; 68:139-148.

7. Coussens PM, Verman N, Coussens MA, Elftman MD, McNulty AM. Cytokine gene expression in peripheral blood mononuclear cells and tissues of cattle infected with Mycobacterium avium subsp. paratuberculosis: evidence for an inherent proinflammatory gene expression pattern. Infect Immun 2004; 72:1409-1422.

8. Verschoor $C P$, Pant SD, You Q, Kelton DF, Karrow NA. Gene expression profiling of PBMCs from Holstein and Jersey cows sub-clinically infected with Mycobacterium avium ssp. paratuberculosis. Vet Immunol Immunopathol 2010; 137:1-11.
9. Woo SR, Sotos J, Hart AP, Barletta R, Gand Czuprynski CJ. Bovine monocytes and a macrophage cell line differ in their ability to phagocytose and support the intracellular survival of Mycobacterium avium subsp. paratuberculosis. Vet Immunol Immunopathol 2006; 110:109-120.

10. Clarke $\mathrm{CJ}$. The pathology and pathogenesis of paratuberculosis in ruminants and other species. J Comp Pathol 1997; 116:217-261.

11. Souza CD, Evanson OA, Weiss DJ. Mitogen activated protein kinasep38 pathway is an important component of the antiinflammatory response in Mycobacterium avium subsp. paratuberculosis-infected bovine monocytes. Microb Pathogen 2006; 41:59-66.

12. Armstrong J, Hart D. Response of cultured macrophages to Mycobacterium tuberculosis, with observations on fusion of lysosomes with phagosomes. J Exp Med 1971; 134:713-740.

13. Souza CD, Weiss DJ, Evanson OA. Role of theMAPK-ERK pathway in regulating cytokine expression by Mycobacterium avium subsp. paratuberculosis- infected bovine monocytes. Am J Vet Res 2007; 68:625-630.

14. Adams JL, Czuprynski CJ. Mycobacterial cell wall components induce the production of TNF-alpha, IL-1, and IL- 6 by bovine monocytes and the murine macrophage cell line RAW 264.7. Microb Pathog 1994; 16:401-411.

15. Souza CD, Evanson OA, Sreevatsan S, Weiss DJ. Cell membrane receptors on bovine mononuclear phagocytes involved in phagocytosis of Mycobacterium avium subsp paratuberculosis. Am J Vet Res 2007; 68:975-980.

16. Whittington RJ, Windsor PA. In utero infection of cattle with Mycobacterium avium subsp. paratuberculosis: a critical review and metaanalysis. Vet J 2009; 179:60-69.

17. Aly SS, Thurmond MC. Evaluation of Mycobacterium avium subsp paratuberculosis infection of dairy cows attributable to infection status of the dam. J Am Vet Med Assoc 2005; 227:450-454. 
18. Wu CW, Livesey $M$, Schmoller SK, Manning EJ, Steinberg $H$, Davis WC, et al. Invasion and persistence of Mycobacterium paratuberculosis during early stages of Johne's disease in calves. Infect Immun 2007; 75:2110-2119.

19. Secott TE, Lin TL, Wu CC. Mycobacterium avium subsp. paratuberculosis fibronectin attachment protein facilitates M-cell targeting and invasion through a fibronectin bridge with host integrins. Infect Immun 2004; 72:3724-3732.

20. Momotani E, Whipple $D L$, Thiermann AB, Cheville NF. Role of M cells and macrophages in the entrance of Mycobacterium paratuberculosis into domes of ileal Peyer's patches in calves. Vet Pathol 1988; 25:131-137.

21. Khalifeh MS, Stabel JR. Effects of gamma interferon, interleukin-10, and transforming growth factor beta on the survival of Mycobacterium avium subsp. paratuberculosis in monocyte-derived macrophages from naturally infected cattle. Infect Immun 2004; 72:1974-1982.

22. Buza JJ, Hikono H, Mori Y. Neutralization of interleukin-10 significantly enhances gamma interferon expression in peripheral blood by stimulation with Johnin purified protein derivative and by infection with Mycobacterium avium subsp. paratuberculosis in experimentally infected cattle with paratuberculosis. Infect Immun 2004; 72:2425-2428.

23. Jorgensen JB. Survival of Mycobacterium paratuberculosis in slurry. Nord Vet Med 1977; 29:267-270.

24. Nigou J, Zelle-Rieser C, Gilleron M, Thurnjer M, Puzo G. Mannosylated lipoarabinomannans inhibit IL-12 production by human dendritic cells: evidence for a negative signal delivered through the mannose receptor. J Immunol 2001; 166:7477-7485.

25. Biet F, Bay S, Thibault VC, Euphrasie D, Grayon M, Ganneau C, et al. Lipopentapeptide induces a strong host humoral response and distinguishes Mycobacterium avium subsp. paratuberculosis from M. avium subsp. avium. Vaccine 2008; 26:257-268.
26. Dheenadhayalan V, Shin KS, Chang CF, Chang CD, Wang SJ, McDonough S, et al. Cloning and characterization of the genes coding for antigen 85A, 85B and 85C of Mycobacterium avium subsp. paratuberculosis. DNA Seq 2002; 13:287-294.

27. Gatfield J, Pieters J. Molecular mechanisms of host-pathogen interaction: entry and survival of mycobacteria in macrophages. Adv Immunol 2003; 81:45-96.

28. Ferwerda G, Kullberg BJ, de Jong DJ, Girardin SE, Langenberg DM, van Crevel $\mathrm{R}$, et al. Mycobacterium paratuberculosis is recognized by Toll-like receptors and NOD2. J Leukoc Biol 2007; 82:1011-1018.

29. Weiss DJ, Souza CD. Review paper: modulation of mononuclear phagocyte function by Mycobacterium avium subsp. paratuberculosis. Vet Pathol 2008; 45:829-841.

30. Weiss DJ, Evanson OA, McClenahan DJ, Abrahamsen MS, Walcheck BK. Regulation of expression of major histocompatibility antigens by bovine macrophages infected with Mycobacterium avium subsp. paratuberculosis or Mycobacterium avium subsp. avium. Infect Immun 2001; 69:1002-1008.

31. Chiodini RJ, Davis WC. The cellular immunology of bovine paratuberculosis: the predominant response is mediated by cytotoxic gamma/delta T lymphocytes which prevent CD4+ activity. Microb Pathog 1992; 13:447-463.

32. Bassey EO, Collins MT. Study of T-lymphocyte subsets of healthy and Mycobacterium avium subsp. paratuberculosis-infected cattle. Infect Immun 1997; 65:4869-4872.

33. Koo HC, Park YH, Hamilton MJ, Barrington GM, Davies CJ, Kim JB, et al. Analysis of the immune response to Mycobacterium avium subsp. paratuberculosis in experimentally infected calves. Infect Immun 2004; 72:6870-6883.

34. Sommer S, Pudrith CB, Colvin CJ, Coussens PM. Mycobacterium avium subspecie paratuberculosis suppresses expression of IL12 p40 and iNOS genes induced by signalling through CD40 in bovine monocyte-derived macrophages. Vet Immunol Immunopathol 2009; 128:44-52. 
35. de Almeida DE, Colvin CJ, Coussens PM. Antigen-specific regulatory $T$ cells in bovine paratuberculosis. Vet Immunol Immunopathol 2008; 125:234-245.

36. Haddad JJ, Saade NE, Safieh-Garanedian B. Interleukin-10 and the regulation of mitogenactivated protein kinases: are these signaling modules targets for the anti-inflammatory action of this cytokine? Cell Signal 2003; 15:255-267.

37. Koul A, Herget T, Klebl B, Ullrich A. Interplay between mycobacteria and host signaling pathways. Nature Rev 2004; 2:189-202.

38. Schorey JS, Cooper AM. Macrophage signaling upon mycobacterial infection: the MAP kinases lead the way. Cell Micro 2003; 5:133-142.

39. Blumenthal A, Ehlers S, Ernst M, Flad HD, Reiling N. Control of mycobacterial replication in human macrophages: roles of extracellular signal-regulated kinases 1 and 2 and p38 mitogen-activated protein kinase pathways. Infect Immun 2002; 70:4961-4967.

40. Khalifeh MS, Stabel JR. Upregulation of transforming growth factor-beta and interleukin-10 in cows with clinical Johne's disease. Vet Immunol Immunopathol 2004: 99:39-46.

41. Hao XR, Cao DL, Hu YW, Li XX, Liu XH, Xiao J, et al. IFN-gamma down-regulates ABCA1 expression by inhibiting LXRalpha in a JAK/ STAT signaling pathway-dependent manner. Atherosclerosis 2009; 203:417-428.

42. Zhao B, Collins MT, Czuprynski CJ. Effects of gamma interferon and nitric oxide on the interaction of Mycobacterium avium subsp. paratuberculosis with bovine monocytes. Infect Immun 1997; 65:1761-1766.

43. McBribe JM, Jung T, de Vries JE, Aversa G. IL-10 alters DC function via modulation of cell surface molecules resulting in impaired T-cell responses. Cell Immunol 2002; 217:162-172.

44. Lei L, Hostetter JM. Limited phenotypic and functional maturation of bovine monocytederived dendritic cells following Mycobacterium avium subspecies paratuberculosis infection in vitro. Vet Immunol Immunopathol 2007; 120:177-186.
45. Olsen I, Boysen P, Kulberg S, Hope JC, Jungersen G, Storset AK. Bovine NK cells can produce gamma interferon in response to the secreted mycobacterial proteins ESAT- 6 and MPP14 but not in response to MPB70. Infect Immun 2005; 73:5628-5635.

46. Conti P, Kempuraj D, Kandere K, Di Gioacchino M, Barbacane RC, Castellani ML, et al. IL-10, an inflammatory/inhibitory cytokine, but not always. Immunol Lett 2003; 86:123-1299.

47. Motiwala AS, Janagama HK, Paustian ML, Zhu X, Bannantine JP, Kapur V, et al. Comparative transcriptional analysis of human macrophages exposed to animal and human isolates of Mycobacterium avium subspecies paratuberculosis with diverse genotypes. Infect Immun 2006; 74:6046-6056.

48. Sut A, Sirugue S, Sixou S, Lakhdar-Ghazal F, Tocanne JF, Laneele G. Mycobacteria glycolipids as potential pathogenity effectors: alterations of model and natural membranes. Biochemisty 1990; 29:8498-8502.

49. Fratazzi C, Arbeit RD, Carini C, BalcewiczSablinska MK, Keane J, Kornfeld H, Remold HG. Macrophage apoptosis in mycobacterial infections. J Leukocyte Biol 1999; 66:763-764.

50. Coussens PM, Pudrith CB, Skovgaard K, Ren X, Suchyta SP, Stabel JR, et al. Johne's disease in cattle is associated with enhanced expression of genes encoding IL-5, GATA-3, tissue inhibitors of matrix metalloproteinases 1 and 2, and factors promoting apoptosis in peripheral blood mononuclear cells. Vet Immunol Immunopathol 2005; 105:221-234.

51. Jahraus A, Tjelle TE, Beerg T, Habermann A, Storrie B, Ulrich O, Griffiths $\mathrm{G}$. In vitro fusion of phagosomes with different endocytic organelles from 3774 macrophages. J Biol Chem 1998; 46:30379-30390.

52. Knutson KL, Hmama Z, Herrera-Velit $P$, Rochford R, Reimer NE. Lipoarabinomannan of Mycobacterium tuberculosis promotes tyrosine dephosphorylation and inhibition of mitogen-activated protein kinase in human mononuclear phagocytes. J Biol Chem 1998; 273:645-652.

53. Hackam DJ, Rotstein OD, Zhang WJ, Demaurex N, Woodside M, Tsai O, et al. Regulation of phagosomal acidification. J Biol Chem 1997; 272:29810-29820. 
54. Coussens PM, Colvin CJ, Wiersma K, Abouzied A, Sipkovsky S. Gene expression profiling of peripheral blood mononuclear cells from cattle infected with Mycobacterium paratuberculosis. Infect Immun 2002; 70:5494-5502.

55. Coussens PM, Colvin CJ, Rosa GJ, Perez Laspiur J, Elftman MD. Evidence for a novel gene expression program in peripheral blood mononuclear cells from Mycobacterium avium subsp. paratuberculosis-infected cattle. Infect Immun 2003; 71:6487-6498.

56. Weiss DJ, Evanson OA, Deng M, Abrahamsen MS. Gene expression and antimicrobial activity of bovine macrophages in responses to Mycobacterium avium subsp. paratuberculosis. Vet Pathol 2004; 41:326-337.

57. Janagama HK, Lamont EA, George S, Bannantine JP, Xu WW, Tu ZJ, et al. Primary transcriptomes of Mycobacterium avium subsp. paratuberculosis reveal proprietary pathways in tissue and macrophages. BMC Genomics 2010; 11:561.
58. Sechi LA, Felis GE, Ahmed N, Paccagnini D, Usai D, Ortu S, et al. Genome and transcriptome scale portrait of sigma factors in Mycobacterium avium subsp. paratuberculosis. Infect Genet Evol 2007; 7:424-432.

59. Gumber S, Taylor DL, Marsh IB, Whittington RJ. Growth pattern and partial proteome of Mycobacterium avium subsp. paratuberculosis during the stress response to hypoxia and nutrient starvation. Vet Microbiol 2009; 133:344-357.

60. Gomes MS, Paul S, Moreira AL, Appelbereg R, Rabinovitch M, Kaplan G: Survival of Mycobacterium avium and Mycobacterium tuberculosis in acidified phagosomes of murine macrophages. Infect Immun 1999; 67:3199-3206. 